\begin{tabular}{|c|c|}
\hline Title & Cell penetrating peptide mediated systemic siRNA delivery to the liver \\
\hline Author(s) & Hay ashi, Y asuhiro; Y amauchi, Jun; Khalil, Ikramy A .; Kaj imoto, Kazuaki; A kita, Hidetaka; Harashima, Hidey oshi \\
\hline Citation & $\begin{array}{l}\text { International Journal of Pharmaceutics, 419(1-2), 308-313 } \\
\text { https://doi.org/10.1016/.ijpharm.2011.07.038 }\end{array}$ \\
\hline Issue Date & 2011-10-31 \\
\hline Doc URL & http:/hdl.handle.net/2115/47472 \\
\hline Tyре & article (author version) \\
\hline File Information & IJP419-1-2_308-313.pdf \\
\hline
\end{tabular}

Instructions for use 


\section{International Journal of Pharmaceutics}

\section{Title:}

Cell penetrating peptide-mediated systemic siRNA delivery to the liver

\section{Authors:}

Yasuhiro Hayashi $^{\mathrm{a}, 1}$, Jun Yamauchi ${ }^{\mathrm{a}, 1}$, Khalil A Ikramy ${ }^{\mathrm{a}}$, Kazuaki Kajimoto ${ }^{\mathrm{a}}$, Hidetaka Akita ${ }^{\mathrm{a}}$ and Hideyoshi Harashima ${ }^{\mathrm{a}}$ *

\section{Institutions:}

${ }^{a}$ Graduate School of Pharmaceutical Sciences, Hokkaido University, Sapporo, Hokkaido, Japan

*To whom correspondence should be addressed:

Laboratory for Molecular Design of Pharmaceutics, Faculty of Pharmaceutical Sciences, Hokkaido University, Kita-12, Nishi-6, Kita-ku, Sapporo, Hokkaido 060-0812, Japan

$\mathrm{Tel}+81-11-706-3919$

Fax $+81-11-706-4879$

E-mail harasima@pharm.hokudai.ac.jp

\section{Footnote:}

Yasuhiro Hayashi and Jun Yamauchi equally contributed to this study. These authors are listed alphabetically in accordance with family name. 


\begin{abstract}
The Cell-penetrating peptide (CPP) is one of the most attractive tools for efficiently delivering biomolecules to a target organnelle. Here, we describe the use of octaarginine (R8)-modified lipid nanoparticles for the efficient and targeted in vivo delivery of siRNA to the liver. In this study, SR-BI (a scavenger receptor class B, member 1) was targeted by this nanoparticle. Our results demonstrate that R8-modified lipid nanoparticles can be used for the efficient and targeted delivery of liver siRNA to induce the specific knock-down of an endogenous gene with minimum liver toxicity and immune response, and that this CPP based technology holds considerable promise for further in vivo biological applications of siRNA.
\end{abstract}

\title{
Keywords:
}

Cell penetrating peptide, octaarginine, siRNA delivery, liver 


\section{Introduction}

Since the first report of the cell-penetrating peptide (CPP) in 1994 (Derossi D et al., 1994), many types of CPPs have shown to improve the intracellular delivery of various biologically active molecules into living cells, with a high degree of efficiency (El-Andaloussi S et al., 2005; Deshayes S et al., 2005), and have more recently been applied to the in vivo delivery of siRNA (Kumar P et al., 2007; Eguchi A et al., 2009; Crombez L et al., 2009; Jarver P et al., 2010). Many kinds of systemic siRNA delivery techniques have been successfully achieved by conjugating compounds such as cholesterol (Soutschek J et al., 2004), polymers (Rozema DB et al., 2007), and targeted ligands (Nishina $\mathrm{K}$ et al., 2008) to siRNA, by forming stable nucleic acid-lipid nanoparticles (SNALP) of siRNA (Zimmermann TS et al., 2006; Semple SC et al., 2010), and by assembling lipid-siRNA complexes (Santel A et al., 2006). Carbon nanotubes have also been used to systemically deliver siRNA (McCarrol J et al., 2010). Despite this progress, CPP mediated systemic siRNA delivery have not been uniformly successful, except for delivery to the brain (Kumar P et al., 2007) and tumors (Crombez L et al., 2009), because most of the CPP mediated in vivo siRNA delivery studies have used a peptide-siRNA complex system, which was only partly protected from degradation in the serum. Therefore, the development of a CPP-mediated systemic siRNA delivery system which fully encapsulates siRNA, remains a major challenge for in vivo applications.

CPPs have unique pharmacokinetic properties as well as cell membrame penetrating properties. Tat (the transduction domain derived from the HIV Tat protein) and the NLS (nuclear localization signal) peptide rapidly accumulate in the kidney, while the nona-arginine (R9) peptide, an arginine-rich peptide, accumulates at high levels in the liver compared to ten of the most commonly used CPPs (Sarko D et al., 2010). We previously showed that octa-arginine (R8) peptide modified liposomes largely accumulated in the liver after intravenous administration and that this depends on the density of the R8 peptide on the liposomal surface (Mudhakir D et al., 2005). We further demonstrated that liposomes modified with a high density 
of R8 peptide are taken up mainly through macropinocytosis, a process that is less susceptible to lysosomal degradation, and that this results in high gene expression in vitro (Khalil IA et al., 2006; Khalil IA et al., 2007). Therefore, we hypothesized that R8 peptide could be used as both a targeting peptide to the liver and to improve intracellular trafficking. We previously showed that R8-modified lipid nanoparticles, in which nucleic acid is condensed with a polycation followed by encapsulation by a lipid envelope, can efficiently encapsulate siRNA and silence the luciferase gene without any detectable cytotoxicity (Nakamura Y et al., 2007; Akita H et al., 2010). In this report, we report on the development of a targeted in vivo siRNA delivery system using R8-modified lipid nanoparticles. The findings indicate that the liver targeting ability of R8-modified lipid nanoparticles causes the specific knock-down of the endogenous gene in primary hepatocytes and in the liver. 


\section{Material and Methods}

\subsection{Reagent}

Dioleoylphosphatidylethanolamine (DOPE) was purchased from Avanti Polar Lipids (Alabaster, AL, U.S.A.). Stearylated-R8 (STR-R8) was purchased from NeoMPS Industries (San Diego, CA, U.S.A.). Cholesteryl-GALA (Cho-GALA) was purchased from Kurabo Industries, Ltd. (Osaka, Japan). Polyethyleneimine (PEI) (average MW 10000) was purchased from Wako Pure Chemicals (Osaka, Japan). [cholesteryl-1,2-3H(N)]-cholesteryl hexadecyl ether ( $\left.\left[{ }^{3} \mathrm{H}\right] \mathrm{CHE}\right)$ was purchased from PerkinElmer Life Science Japan (Tokyo, Japan). Anti-SR-BI SiRNA (21-mer, 5'-GUCGCAUGGCUCAGAGAGUTT-3', , 5'-ACUCUCUGAGCCAUGCGACTT-3'), Cy3-labeled anti-SR-BI siRNA (21-mer, 5'-GUCGCAUGGCUCAGAGAGUTT-3' ， 5'-Cy3-ACUCUCUGAGCCAUGCGACTT-3'), and anti-lucferase siRNA (21-mer, 5'-GCGCUGCUGGUGCCAACCCTT-3', , 5'-GGGUUGGCACCAGCAGCGCTT -3') were obtained from Hokkaido System Science (Sapporo, Japan). PolyI:C was obtained from SIGMA-Aldrich Co. (St.Louis, MO, USA). All other reagents were commercially available reagent-grade products.

\subsection{Animals}

Male ICR mice (4-5 weeks old) and female C57BL/6 mice (6-7 weeks old) were obtained from Japan SLC (Shizuoka, Japan). The experimental protocols were reviewed and approved by the Hokkaido University Animal Care Committee in accordance with the guidelines for the care and use of laboratory animals.

\subsection{Preparation of R8-modified lipid nanoparticles}

R8-modified lipid nanoparticles were prepared by the hydration method as described previously (Nakamura Y et al., 2007). In brief, a PEI solution $(1 \mathrm{mg} / \mathrm{mL})$ was added to the siRNA solution $(2 \mathrm{mg} / \mathrm{mL})$ under vortexing at a nitrogen/phosphate $(\mathrm{N} / \mathrm{P})$ ratio of 1.8 . A lipid 
film was then formed by evaporating an ethanol solution (312.5 nmol total lipids), composed of STR-R8, DOPE, and Cho-GALA (molar ratio of STR-R8/DOPE/Cho-GALA: 18:77.5:4.5). The siRNA/PEI complex (50 $\mu \mathrm{g}$ siRNA) was applied to the lipid film, followed by incubation for 5-10 min at room temperature to hydrate the lipids. To coat the siRNA/PEI complex with the lipid, the lipid film was sonicated for approximately $1 \mathrm{~min}$ in a bath-type sonicator (AU-25, AIWA Co., Tokyo, Japan). The average diameter and zeta-potential of the nanoparticles were determined using a Zetasizer Nano ZS instrument (Worchestershire, U.K.).

\subsection{Pharmacokinetics and biodistribution experiment in mice}

R8-modified lipid nanoparticles were prepared with a non-exchangeable lipid label $\left[{ }^{3} \mathrm{H}\right] \mathrm{CHE}$ incorporated. The labeled nanoparticles containing $80 \mu \mathrm{g}$ of siRNA were injected via the tail vein of ICR mice. At the indicated times, the mice were sacrificed and blood, liver, lung, splen, and kidney were collected. After weighing the tissue samples, approximately $0.2 \mathrm{~g}$ of tissue samples (in the case of blood samples, $20 \mu \mathrm{L}$ ) were solubilized in $2 \mathrm{~mL}$ of Soluene-350 overnight at $55{ }^{\circ} \mathrm{C}$. All samples were decolorized by treatment with $\mathrm{H}_{2} \mathrm{O}_{2}$. The radioactivity was determined by liquid scintillation counting (LSC-6100; ALOKA CO, Ltd., Tokyo, Japan) after adding $10 \mathrm{~mL}$ of scintillation fluid (Hionic fluor; Perkin Elmer, Inc., MA, U.S.A.) to the scintillation vials. Blood concentration and tissue accumulation is represented as the percent of the initially injected dose (\% ID/mL and \% ID/tissue, respectively).

\subsection{Primary hepatocyte culture and R8 peptide-mediated siRNA transfection study}

Primary hepatocytes were collected from ICR mice 7 to 8 weeks of age, as described previously (Ukawa M et al., 2010). After checking for cell viability and cell numbers, $5 \times 10^{5}$ cells were seeded on a $100 \mathrm{~mm}$ plate in $10 \mathrm{~mL}$ of culture medium (William's E medium with antibiotics, $10 \%$ serum, $1 \mathrm{nM}$ insulin and $1 \mathrm{nM}$ dexamethazone) for $3 \mathrm{~h}$. The cells were washed in phosphate-buffered saline (PBS) to remove dead cells. The indicated dose of siRNA 
containing nanoparticles was then added to the cell culture medium (the concentration of FBS was fixed $10 \%$ in all samples) and the suspension then incubated in a $\mathrm{CO}_{2}$ incubator for 24 hours.

\subsection{R8 peptide-mediated siRNA delivery in mice}

C57BL/6 mice (6-7 weeks old) were treated with $100 \mu \mathrm{g}$ or $50 \mu \mathrm{g}$ or $25 \mu \mathrm{g}$ siRNA in a 500 $\mu \mathrm{L}$ injection volume by intravenous injection. The mice were killed $24 \mathrm{~h}$ after the treatment, and blood and liver were collected. Liver samples were stored in RNAlater solution.

\subsection{Measurement of serum biochemical value and cytokine}

Blood samples were centrifuged at $10000 \mathrm{rpm}, 4{ }^{\circ} \mathrm{C}, 10 \mathrm{~min}$ to separate serum. GPT and GOT levels in serum were measured using a transaminase C II test kit (Wako Pure Chemicals, Osaka, Japan) and IL-6 and IFN-gamma levels in serum were determined with ELISA kits (R\&D systems, Inc.Minneapolis, USA), according to manufacturer's instructions.

\subsection{Real time RT-PCR analysis}

Total RNA was extracted from primary hepatocytes and liver tissue with the TRIzol Reagent (Invitrogen, CA, USA) according to the manufacturer's recommended procedures. The cDNA was synthesized using a High Capacity RNA-to-cDNA Kit (Applied Biosystems, Foster City, CA, USA). Amplification of the SR-BI fragment was performed with the forward primer (5'-TCCAGCCTGACAAGTCGCATGG-3') and the reverse primer (5'-GCTTGCTCTCCATCAATATCGAGCC-3'), and beta-actin as an internal control was performed with the forward primer (5'-GAAGGAGATTACTGCTCTGG-3') and the reverse primer (5'-ACACAGAGTACTTGCGCTCA-3') using the SYBR Green Realtime PCR Master Mix instrument (TOYOBO, Osaka, Japan). PCR was performed using the Mx3005P Real-time QPCR system (Agilent, Foster City, CA, U.S.A.) : a 10-min pre-incubation at $95{ }^{\circ} \mathrm{C}$, followed 
by 40 cycles of $95^{\circ} \mathrm{C}$ for $15 \mathrm{~s}$ and $60{ }^{\circ} \mathrm{C}$ for $1 \mathrm{~min}$. Data were analyzed using the comparative $\Delta \Delta \mathrm{Ct}$ method.

\subsection{Analysis of lysosomal localization}

To examine the intracellular trafficking of R8-modified lipid nanoparticles, $1 \times 10^{5}$ primary hepatocyte cells were seeded on a $35 \mathrm{~mm}$ glass base dish (IWAKI, Osaka, Japan) in $2 \mathrm{ml}$ of culture medium. Cy3-labeled siRNA loaded R8-modified lipid nanoparticles (100nM) were incubated with cells in $1 \mathrm{ml}$ of culture medium for $1.5 \mathrm{~h}$ at $37{ }^{\circ} \mathrm{C}, 5 \% \mathrm{CO}_{2}$. To stain the nuclei and endosomes, the cells were incubated with culture medium containing $5 \mu \mathrm{g} / \mathrm{ml}$ Hoechst 33342 and $2 \mu \mathrm{g} / \mathrm{ml}$ Lysotracker Green for $30 \mathrm{~min}$ at $37{ }^{\circ} \mathrm{C}, 5 \% \mathrm{CO}_{2}$. After washing the cells 3 times with PBS supplemented with heparin (40 Unit/ml) to remove nanoparticles that were bound to the cell membrane, the medium was changed to observation buffer ( $135 \mathrm{mM} \mathrm{NaCl}, 5.4$ $\mathrm{mM} \mathrm{KCl}, 1 \mathrm{mM} \mathrm{MgCl} 2,1.8 \mathrm{mM} \mathrm{CaCl}_{2}, 5 \mathrm{mM}$ HEPES, $10 \mathrm{mM}$ Glucose, $\mathrm{pH}$ 7.3) and the cells were observed by confocal laser scanning microscopy (Nikon A1; Nikon Co, Ltd., Tokyo, Japan)

\subsection{Statistical analysis}

Statistical comparisons were performed by one-way ANOVA, followed by Student's t-test for the two groups. 


\section{Results}

\subsection{Physicochemical characterization of R8-modified lipid nanoparticles}

The physical characteristics of the R8-modified lipid nanoparticles used in this study are shown in Table 1. The initially prepared siRNA core had a particle size of $90 \mathrm{~nm}$ and a zeta-potential of $-30 \mathrm{mV}$. After coating the particle with lipids, the particle size increased to approximately $160 \mathrm{~nm}$ and the zeta-potential was inverted to $+40 \mathrm{mV}$. This suggests that the siRNA core was encapsulated by the lipid envelope.

\subsection{Blood clearance and biodistribution studies}

To determine the in vivo distribution of R8-modified lipid nanoparticles, the mice were injected with [3H]-CHE-labeled nanoparticles via a tail vein injection. The resulting clearance property is described in Fig.1 (a). The plasma half-life value, using a one compartmental model, was caluculated as $6.3 \mathrm{~min}$. On the other hand, R8-modified lipid nanoparticles rapidly accumulated in the liver (44 $\pm 2 \%$ injected dose per organ) at $10 \mathrm{~min}$ (Fig.1 (b)). The biodistribution of liver, lung, spleen, kidney, tissues that are well-known as first-pass organs, $1 \mathrm{~h}$ after administration is shown in Fig.1 (c). The accumulation in the liver was significantly higher compared to other tissues, indicating that R8-modified lipid nanoparticle system has a high selectivity for the liver.

\section{3. $\mathrm{R8}$ peptide-mediated delivery of siRNA in primary hepatocyte}

Dose-response experiments performed on primary hepatocytes revealed that the R8 peptide-mediated delivery of SR-BI siRNA induced a significant reduction in SR-BI mRNA at a dose of more than $25 \mathrm{nM}$ (36\% reduction compared to non-treatment) (Fig.2). In contrast, no significant silencing was observed in the case of $100 \mathrm{nM}$ of luc siRNA compared to non-treatment although there was slight reduction in SR-BI mRNA (23\% reduction compared 
to non-treatment). To investigate the intracellular trafficking fate of siRNA, their colocalization with the lysosomal compartment was evaluated (Fig.3). Most of the Cy3-labeled siRNA (Red-dots) was not colocalized with the lysosomal compartment (Green-dots) although a few dots were colocalized (yellow-dots), demonstrating that R8-modified lipid nanoparticles can be used for the efficient delivery of siRNA to the cytosol.

\subsection{In vivo $R 8$ peptide-mediated SR-BI siRNA delivery}

To assess the ability of R8 peptide-mediated siRNA delivery in vivo, R8-modified lipid nanoparticles containing SR-BI siRNA were injected into mice by using a single injection via the tail vein. As shown in Fig.4 (a), a dose-dependent reduction in SR-BI mRNA was observed (45\% silencing observed at $25 \mu \mathrm{g}$ of siRNA, and $75 \%$ silencing achieved at $100 \mu \mathrm{g}$ of siRNA). In contrast, no significantly detectable reduction was observed with only HEPES buffer or luc siRNA loaded nanoparticles (Fig.4 (b)), indicating that the silencing is specific to the SR-BI gene.

\subsection{Evaluation of toxicity}

GPT and GOT levels in mouse serum were determined $24 \mathrm{~h}$ after R8 peptide-mediated siRNA delivery. GPT and GOT are respectively regarded as reliable indicators of liver tissue damage and more general, systemic tissue damage. As shown in Table 2, the levels of both proteins in the R8 peptide-modified nanoparticle treated mice were not significantly increased compared to non-treatment or Hepes buffer treated mice. Furthermore, the IL-6 and IFN-gamma levels in mouse serum were measured $6 \mathrm{~h}$ and $24 \mathrm{~h}$ (Table 3 ). When mice were treated with R8-modified lipid nanoparticles containing $100 \mu \mathrm{g}$ of siRNA, these IL-6 levels were slightly increased at $6 \mathrm{~h}$, but these numbers were significantly lower compared to the treatment of poly IC $(\mathrm{p}<0.001)$. This level was back to almost normal level at $24 \mathrm{~h}$. On the other hand, the production of IFN-gamma was no detectable in either case. Therefore, the R8 peptide-mediated siRNA 
delivery system can be assumed to be well tolerated for immune response as well as liver toxicity. 


\section{Discussion}

The findings reported herein show that R8-modified lipid nanoparticles may enable the deliver siRNA to the liver. When siRNA is delivered in this way, it is capable of silencing the expression of SR-BI in both either primary hepatocytes and the liver with minimum liver toxicity. The key features of these R8-modified lipid nanoparticles are as follows: (i) this system has ability to target in the liver rapidly within 10-20 min (Fig.1 (b) and (c)). This liver targeting ability can be attributed to the high density of the R8 peptide (more than $10 \%$ of modification of total lipids) on the surface of the nanoparticles (Mudhakir D et al., 2005). (ii) the system delivers siRNA to the cytosol quite efficiently. Imaginig data revealed that most of the siRNAs were not colocalized in the lysosomal compartment (Fig.3), which is consistent with previous reports indicating that a high density of $\mathrm{R} 8$ peptide on the surface of nanoparticle facilitates the induction of macropinocytosis, which is an advantageous route for efficient intracellular trafficking, and which stimulates efficient endosomal escape (Khalil IA et al., 2006; El-Sayed A et al., 2008). (iii) there is no need to use chemically modified siRNA (Braasch DA et al., 2003) to protect against degradation in the serum because siRNA is efficiently encapsulated within a nanoparticle (Nakamura Y et al., 2007).

Delivery of the SR-BI siRNA caused significant knockdown, which was dependent on the amount of nanoparticles employed (Fig.4). A Cy3-siRNA signal was detected in isolated hepatocytes after injection via the tail vein (data not shown). Although SR-BI is mainly expressed in hepatocytes (Hoekstra M et al., 2003), the contribution of endothelial cells and Kupffer cells was also take into consideration because this type of nanoparticle is highly positively charged (Table 1). Further experiments will be needed to investigate the knockdown contribution of hepatocytes and non-parenchymal cells, and to refine the intrahepatic selective delivery by using a target ligand or biodegradable polyethyleneglycol (PEG) to avoid recognition by kupffer cells.

The hepatotoxicity and innate immune response of R8-modified lipid nanoparticles were 
assessed. It has been reported that intravenous injection of cationic nanoparticles encapsulating pDNA without PEG modification induced proinflammatory cytokines as well as hepatic toxicity (Hatakeyama $\mathrm{H}$ et al., 2011). In contrast, in the case of siRNA systems, IL-6 and IFN-gamma responses were greatly reduced (Table 3). In particular, the level of IFN-gamma was not detectable when delivering R8-modified lipid nanoparticles. This phenomenon is very surprising because the production of IFN-gamma is usually detected on the intravenous injection of liposome/siRNA complex (Sato A et al., 2007) or siRNA encapsulated nanoparticles (Zimmermann TS et al., 2006). These observations suggest that siRNA may be safer than pDNA even when the cationic nanoparticle systems without PEG modification are used and R8-modified lipid nanoparticles may be tolerated by the immune response. Further studies will be needed to completely inhibit these toxicity parameters for the safe siRNA delivery systems. The modification of PEG or a biocompatible material is one such example.

In conclusion, we report on the development of an R8 peptide-mediated siRNA delivery system that targets the liver. The system significantly silences endogenous genes at low effective concentrations of siRNA ( $25 \mu \mathrm{g} /$ mouse) in only a single treatment, and no evidence was found for liver toxicity. These results provide the first evidence to demonstrate that R8-modified lipid nanoparticles can be safely and effectively used to systemically deliver siRNA to the liver, and opens the way to the development of more efficient CPP-mediated siRNA delivery systems for widespread applications, in both experimental biology and molecular medicine. 


\section{Acknowledgements}

This work was supported by the Special Education and Research Expenses of the Ministry of Education, Culture, Sports, Science and Technology of Japan, and the Matching Program for Innovations in Future Drug Discovery and Medical Care, and a Grant-in-Aid for Young Scientists (Start-up). We also thank Dr. Milton Feather for editing this manuscript. 
Table 1

Physicochemical properties of the R8-modified lipid nanoparticles

\begin{tabular}{cccc}
\hline & size $(\mathrm{nm})$ & z-potential $(\mathrm{mV})$ & PdI \\
\hline siRNA/ PEI core & $89 \pm 10$ & $-27 \pm 3$ & $0.22 \pm 0.01$ \\
\hline R8-modified lipid nanoparticles & $162 \pm 8$ & $38 \pm 4$ & $0.21 \pm 0.04$ \\
\hline & & & \\
\hline
\end{tabular}

Table 2

GPT and GOT levels in mouse serum $24 \mathrm{~h}$ after R8 peptide-mediated siRNA (100 $\mu \mathrm{g})$ delivery

\begin{tabular}{lcc}
\hline & GPT (IU/L) & GOT (IU/L) \\
\hline Non-treatment & $4.3 \pm 0.9$ & $6.1 \pm 2.8$ \\
Hepes buffer & $6.5 \pm 2.6$ & $8.9 \pm 4.8$ \\
luc siRNA & $9.9 \pm 1.3$ & $20.9 \pm 12.9$ \\
SR-BI siRNA & $5.7 \pm 2.4$ & $18.2 \pm 9.3$ \\
\hline Data are presented as the mean \pm SD $(\mathrm{n}=3)$.
\end{tabular}

Table 3

IL-6 and IFN-gamma levels for the R8-modified lipid nanoparticles (100 $\mu$ g siRNA)- or poly IC $(10 \mu \mathrm{g})$-treated mice.

\begin{tabular}{lccc}
\hline Treatment & Cytokine type & Time & $\mathrm{pg} / \mathrm{mL}$ \\
\hline MEND & IL-6 & $0 \mathrm{~h}$ & N.D. \\
& & $6 \mathrm{~h}$ & $119 \pm 51$ \\
& & $24 \mathrm{~h}$ & $11+4$ \\
& IFN-gamma & $0 \mathrm{~h}$ & N.D. \\
& & $6 \mathrm{~h}$ & N.D. \\
& & $24 \mathrm{~h}$ & N.D. \\
\hline poly IC & IL-6 & $6 \mathrm{~h}$ & $1508 \pm 417$ \\
\hline
\end{tabular}

Data are presented as the mean \pm SD $(n=4)$. 


\section{Figure legends}

Fig.1 Pharmacokinetics and biodistribution of R8-modified lipid nanoparticles in mice.

(a) Plasma clearance and (b) liver biodistribution of ${ }^{3} \mathrm{H}-\mathrm{CHE}-$ labeled nanoparticles in mice.

Each mouse was injected with nanoparticles containing $80 \mu \mathrm{g}$ of siRNA via the tail vein. (c) Tissue distribution was analyzed $1 \mathrm{~h}$ after treatment. Data are expressed as mean $\pm \mathrm{SD}\left(\mathrm{n}=3,{ }^{*}\right.$ $\mathrm{P}<0.01)$.
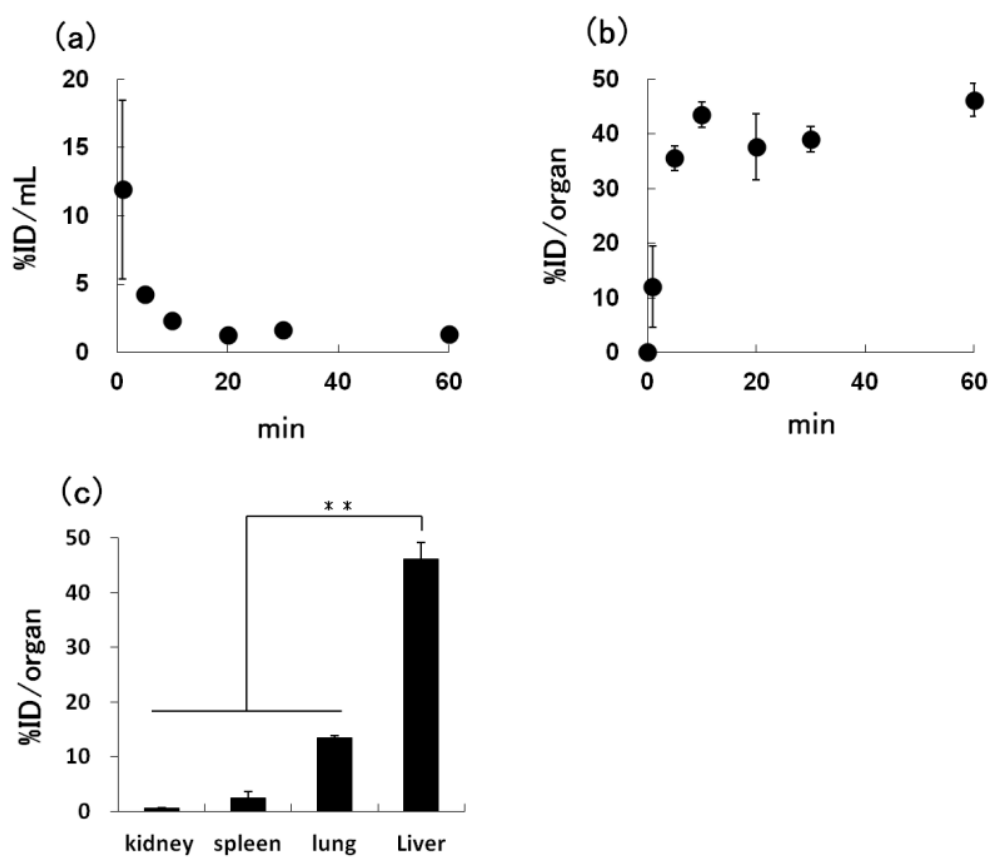

Fig.2 R8 peptide-mediated gene-silencing in mouse primary hepatocyte.

Primary hepatocytes were treated with nanoparticles containing SR-BI siRNA for $24 \mathrm{~h}$. SR-BI mRNA levels normalized to beta-actin mRNA measured $24 \mathrm{~h}$ after transfection. Data are shown as mean $\pm \operatorname{SD}(n=3)$. 


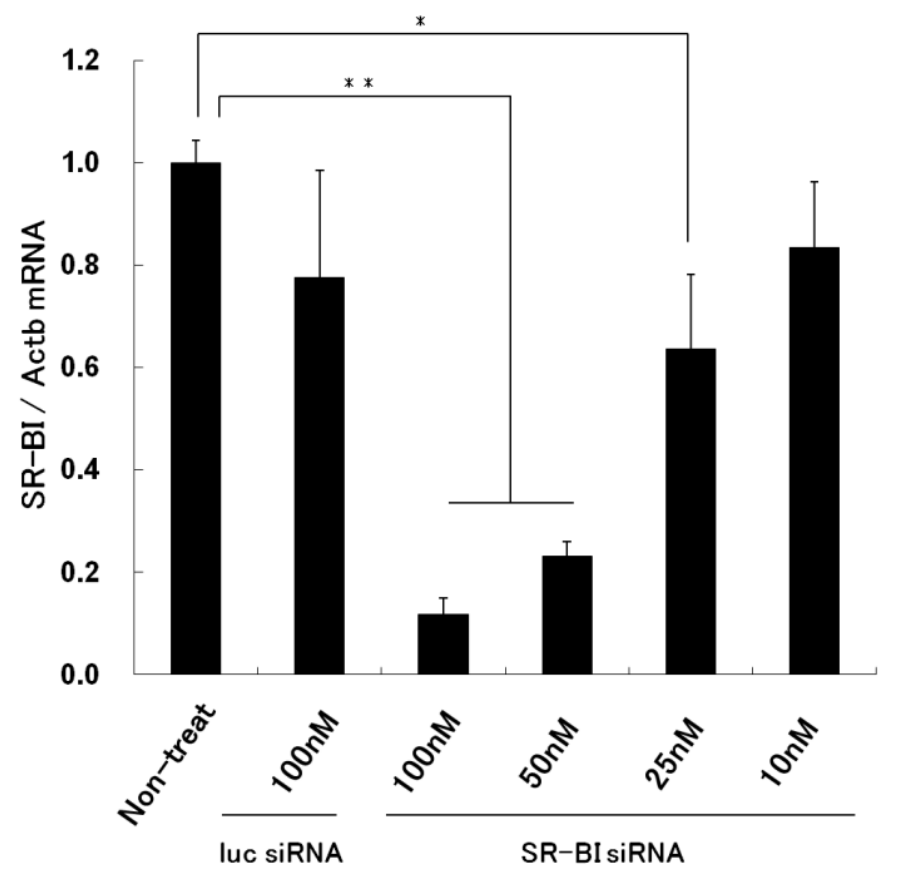

Fig.3 Lysosomal localization of R8-modified lipid nanoparticles.

Primary hepatocytes were incubated with Cy3-labeled siRNA loaded nanoparticles for $1.5 \mathrm{~h}$. The lysosomal localization of siRNA was analyzed by means of confocal microscopy. The lysosomal compartment were stained with Lysotracker Green and nuclei were stained with Hoechst 33342. Bar indicates $50 \mu \mathrm{m}$.

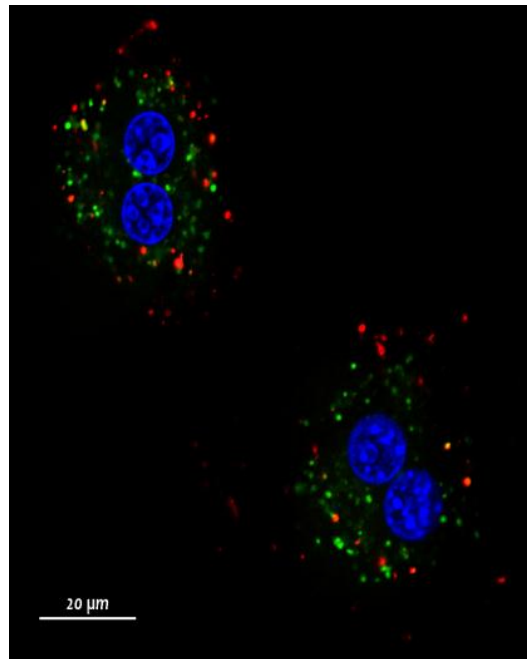


Fig.4 R8 peptide-mediated silencing of SR-BI in mice.

Liver SR-BI mRNA levels normalized to beta-actin mRNA measured $24 \mathrm{~h}$ after single intravenous injections. (a) dose-dependent and (b) gene-specific silencing were observed. Data are expressed as mean $\pm \mathrm{SD}\left(\mathrm{n}=3,{ }^{*} \mathrm{P}<0.05,{ }^{* *} \mathrm{P}<0.01\right)$.
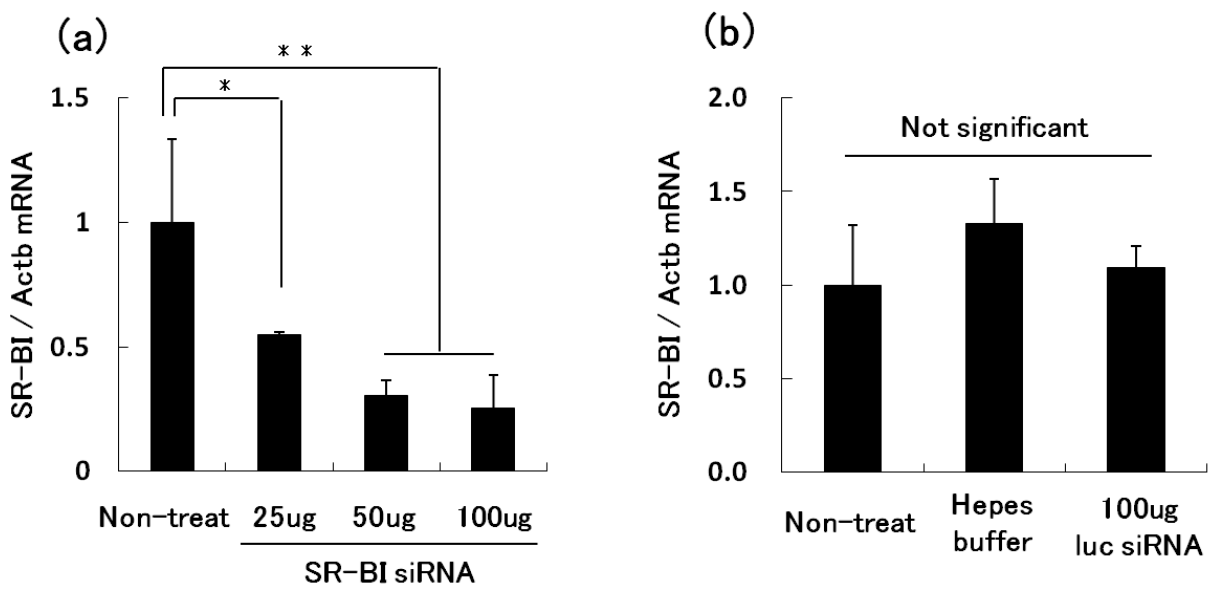


\section{References}

Akita, H., Kogure, K., Moriguchi, R., Nakamura, Y., Higashi, T., Nakamura, T., Serada, S., Fujimoto, M., Naka, T., Futaki, S., Harashima, H., 2010. Nanoparticles for ex vivo siRNA delivery to dendritic cells for cancer vaccines: programmed endosomal escape and dissociation. J. Control. Release. 143, 311-7.

Braasch, DA., Jensen, S., Liu, Y., Kaur, K., Arar, K., White, MA., Corey, DR., 2003. RNA interference in mammalian cells by chemically-modified RNA. Biochemistry. 42, 7967-75.

Crombez, L., Morris, MC., Dufort, S., Aldrian-Herrada, G., Nguyen, Q., Mc Master, G., Coll, JL., Heitz, F., Divita, G., 2009. Targeting cyclin B1 through peptide-based delivery of siRNA prevents tumor growth. Nucleic Acids Res. 37, 4559-69.

Derossi, D., Joliot, AH., Chassaing, G., Prochiantz, A., 1994. The third helix of the Antennapedia homeodomain translocates through biological membranes. J. Biol. Chem. 269, 10444-50.

Deshayes, S., Morris, MC., Divita, G., Heitz, F., 2005. Cell-penetrating peptides: tools for intracellular delivery of therapeutics. Cell. Mol. Life. Sci. 62, 1839-49.

Eguchi, A., Meade, BR., Chang, YC., Fredrickson, CT., Willert, K., Puri, N., Dowdy, SF., 2009. Efficient siRNA delivery into primary cells by a peptide transduction domain-dsRNA binding domain fusion protein. Nat. Biotechnol. 27, 567-71.

El-Andaloussi, S., Holm, T., Langel, U., 2005. Cell-penetrating peptides: mechanisms and applications. Curr. Pharm. Des. 11, 3597-611.

El-Sayed, A., Khalil, IA., Kogure, K., Futaki, S., Harashima, H., 2008. Octaarginine- and octalysine-modified nanoparticles have different modes of endosomal escape. J. Biol. Chem. $283,23450-61$.

Hatakeyama H., Ito E., Yamamoto M., Akita H., Hayashi Y., Kajimoto K., Kaji N., Baba Y., Harashima H., 2011. A DNA Microarray-based Analysis of the Host Response to a Nonviral Gene Carrier: A Strategy for Improving the Immune Response. Mol Ther. [Epub ahead of 
print].

Hoekstra, M., Kruijt, JK., Van, Eck, M., Van, Berkel, TJ., 2003. Specific gene expression of ATP-binding cassette transporters and nuclear hormone receptors in rat liver parenchymal, endothelial, and kupffer cells. J. Biol. Chem. 278, 25448-53.

Jarver, P., Mager, I., Langel, U., 2010. In vivo biodistribution and efficacy of peptide mediated delivery. Trends. Pharmacol. Sci. 31, 528-35.

Kakudo, T., Chaki, S., Futaki, S., Nakase, I., Akaji, K., Kawakami, T., Maruyama, K., Kamiya, H., Harashima, H., 2004. Transferrin-modified liposomes equipped with a $\mathrm{pH}$-sensitive fusogenic peptide : an artificial viral-like delivery system. Biochemistry. 43, 5618-28.

Khalil, IA., Kogure, K., Futaki, S., Harashima, H., 2006. High density of octaarginine stimulates macropinocytosis leading to efficient intracellular trafficking for gene expression J. Biol. Chem. 281, 3544-51.

Khalil, IA., Korure, K., Futaki, S., Hama, S., Akita, H., Ueno, M., Kishida, H., Kudoh, M., Mishina, Y., Kataoka, K., Yamada, M., Harashima, H., 2007. Octaarginine-modified multifunctional envelope-type nanoparticles for gene delivery. Gene Ther. 14, 682-9.

Kumar, P., Wu, H., McBride, JL., Jung, KE., Kim, MH., Davidson, BL., Lee, SK., Shankar, P., Manjunath, N., 2007. Transvascular delivery of small interfering RNA to the central nervous system. Nature. 448, 39-43.

McCarrol, J., Baigude, H., Yang, CS., Rana, TM., 2010. Nanotubes functionalized with lipids and natural amino acid dendrimers: a new strategy to create nanomaterials for delivering systemic RNAi. Bioconjug. Chem. 21, 56-63.

Mudhakir, D., Akita, H., Khalil, IA., Futaki, S., Harashima, H., 2005. Pharmacokinetic analysis of the tissue distribution of octaarginine modified liposomes in mice. Drug. Metab. Pharmacokinet. 20, 275-81.

Nakamura, Y., Kogure, K., Futaki, S., Harashima, H., 2007. Octaarginine-modified multifunctional envelope-type nano device for siRNA. J. Control. Release. 119, 360-7. 
Nishina, K., Unno, T., Uno, Y., Kubodera, T., Kanouchi, T., Mizusawa, H., Yokota, T., 2008. Efficient in vivo delivery of siRNA to the liver by conjugation of alpha-tocopherol. Mol. Ther. 16, 734-40.

Rozema, DB., Lewis, DL., Wakefield, DH., Wong, SC., Klein, JJ., Roesch, PL., Bertin, SL., Reppen, TW., Chu, Q., Blokhin, AV., Hagstrom, JE., Wolff, JA., 2007. Dynamic PolyConjugates for targeted in vivo delivery of siRNA to hepatocytes. Proc. Natl. Acad. Sci. USA. 104, $12982-7$.

Santel, A., Aleku, M., Keil, O., Endruschat, J., Esche, V., Fisch, G., Dames, S., Loffler, K., Fechtner, M., Arnold, W., Giese, K., Klippel, A., Kaufmann, J., 2006. A novel siRNA-lipoplex technology for RNA interference in the mouse vascular endothelium. Gene Ther. 13, 1222-34.

Sarko, D., Beijer, B., Garcia, Boy, R., Nothelfer, EM., Leotta, K., Eisenhut, M., Altmann, A., Haberkorn, U., Mier, W., 2010. The pharmacokinetics of cell-penetrating peptides. Mol. Pharm. 7, 2224-31.

Sato, A., Takagi, M., Shimamoto, A., Kawakami, S., Hashida, M., 2007. Small interfering RNA delivery to the liver by intravenous administration of galactosylated cationic liposomes in mice. Biomaterials. 28, 1434-42.

Semple, SC., Akinc, A., Chen, J., Sandhu, AP., Mui, BL., Cho, CK., Sah, DW., Stebbing, D., Crosley, EJ., Yaworski, E., HafezIM, Dorkin, JR., Qin, J., Lam, K., Rajeev, KG., Wong, KF., Jeffs, LB., Nechev, L., Eisenhardt, ML., Jayaraman, M., Kazem, M., Maier, MA., Srinivasulu, M., Weinstein, MJ., Chen, Q., Alvarez, R., Barros, SA., De, S., Klimuk, SK., Borland, T., Kosovrasti, V., Cantley, WL., Tam, YK., Manoharan, M., Ciufolini, MA., Tracy, MA., de, Fougerolles, A., MacLachlan, I., Cullis, PR., Madden, TD., Hope, MJ., 2010. Rational design of cationic lipids for siRNA delivery. Nat. Biotechnol. 28, 172-6.

Soutschek, J., Akinc, A., Bramlage, B., Charisse, K., Constien, R., Donoghue, M., Elbashir, S., Geick, A., Hadwiger, P., Harborth, J., John, M., Kesavan, V., Lavine, G., Pandey, RK., 
Racie, T., Rajeev, KG., Rohl, I., Toudjarska, I., Wang, G., Wuschko, S., Bumcrot, D., Koteliansky, V., Limmer, S., Manoharan, M., Vornlocher, HP., 2004. Therapeutic silencing of an endogenous gene by systemic administration of modified siRNAs. Nature. 432, $173-8$.

Ukawa, M., Akita, H., Masuda, T., Hayashi, Y., Konno, T., Ishihara, K., Harashima, H., 2010. 2-Methacryloyloxyethyl phosphorylcholine polymer (MPC)-coating improves the transfection activity of GALA-modified lipid nanoparticles by assisting the cellular uptake and intracellular dissociation of plasmid DNA in primary hepatocytes. Biomaterials. 31, 6355-62.

Zimmermann, TS., Lee, AC., Akinc, A., Bramlage, B., Bumcrot, D., Fedoruk, MN., Harborth, J., Heyes, JA., Jeffs, LB., John, M., Judge, AD., Lam, K., McClintock, K., Nechev, LV., Palmer, LR., Racie, T., Rohl, L., Seiffert, S., Shanmugam, S., Sood, V., Soutschek, J., Toudjarska, I., Wheat, AJ., Yaworski, E., Zedalis, W., Koteliansky, V., Manoharan, M., Vornlocher, HP., MacLachlan, I., 2006. RNAi-mediated gene silencing in non-human primates, Nature. $441,111-4$. 